\title{
Regional estimation of daily to annual regional evapotranspiration with MODIS data in the Yellow River Delta wetland
}

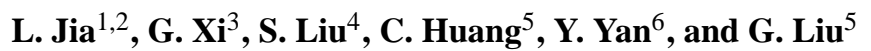 \\ ${ }^{1}$ Alterra, Wageningen University and Research Centre, The Netherlands \\ ${ }^{2}$ State Key Laboratory of Remote Sensing Science, Institute of Remote Sensing Applications, \\ Chinese Academy of Sciences, Beijing, China \\ ${ }^{3}$ National Marine Data \& Information Service, Tianjin, China \\ ${ }^{4}$ State key Laboratory of Remote Sensing Science, School of Geography, Beijing Normal University, Beijing, China \\ ${ }^{5}$ Institute of Geographical Sciences and Natural Resources Research, Chinese Academy of Sciences, Beijing, China \\ ${ }^{6}$ China National Climate Centre, Beijing, China
}

Received: 17 February 2009 - Published in Hydrol. Earth Syst. Sci. Discuss.: 13 March 2009

Revised: 18 August 2009 - Accepted: 8 September 2009 - Published: 5 October 2009

\begin{abstract}
Evapotranspiration (ET) from the wetland of the Yellow River Delta (YRD) is one of the important components in the water cycle, which represents the water consumption by the plants and evaporation from the water and the non-vegetated surfaces. Reliable estimates of the total evapotranspiration from the wetland is useful information both for understanding the hydrological process and for water management to protect this natural environment. Due to the heterogeneity of the vegetation types and canopy density and of soil water content over the wetland (specifically over the natural reserve areas), it is difficult to estimate the regional evapotranspiration extrapolating measurements or calculations usually done locally for a specific land cover type. Remote sensing can provide observations of land surface conditions with high spatial and temporal resolution and coverage. In this study, a model based on the Energy Balance method was used to calculate daily evapotranspiration (ET) using instantaneous observations of land surface reflectance and temperature from MODIS when the data were available on clouds-free days. A time series analysis algorithm was then applied to generate a time series of daily ET over a year period by filling the gaps in the observation series due to clouds. A detailed vegetation classification map was used to help identifying areas of various wetland vegetation types in the YRD wetland. Such information was also used to improve the parameterizations in the energy balance model to improve the accuracy of ET estimates.
\end{abstract}

Correspondence to: L. Jia

(li.jia@wur.nl)
This study showed that spatial variation of ET was significant over the same vegetation class at a given time and over different vegetation types in different seasons in the YRD wetland.

\section{Introduction}

The Yellow River runs into the Bohai Sea between the Bohai gulf and the Laizhou gulf, forming one of the widest, most integrated and youngest natural wetland ecosystems in China. Recently, because of the decreasing supply of water and sediments, dike construction along the river, agriculture expansion and urbanization, the wetland ecosystem in the Yellow River Delta (YRD) is under a significant environmental stress. Rational use of water resource is becoming an important issue recently in this region. Evapotranspiration (ET) from the wetland of the Yellow River Delta (YRD) is one of the important components in the water cycle, which represents the water consumption by the plants and the evaporation from the water and the non-vegetated surfaces. Evapotranspiration is an essential variable in understanding water and vegetation dynamics in wetlands and in regulating water supplies between the multi-purpose uses. Better understanding of wetland response under different water supply and consumption scenarios will help the water authority to manage the water in different seasons on a scientific basis.

Considerable efforts have been made by scientific community to develop algorithms for estimating spatially and temporally distributed evapotranspiration using land surface biophysical parameters provided by remote sensed

Published by Copernicus Publications on behalf of the European Geosciences Union. 
spectral information. Widely used algorithms that utilize visible/near-infrared and thermal spectral measurements include energy balance based (single- and dual-source) models (Norman et al., 1995; Bastiaanssen et al., 1998a, b; Kustas and Norman, 1999; Jia et al., 2001; Jia, 2004; Su, 2002, 2005), trapezoid or triangle methods (Nemani and Running, 1989; Moran et al., 1994; Gillies and Carlson, 1995; Jiang and Islam, 1999; Nishida et al., 2003), and simple imagedependent algorithms (Roerink et al., 2000a).

Most recently, interest has been drawn back to the use of Penman-Monteith equation in combination of remote sensed plant growth information, i.e. LAI, and routine meteorological measurements to estimate actual daily evapotranspiration at regional scale (Cleugh et al., 2007; Mu et al., 2007; Leuning et al., 2008). Though surface thermal dynamics can be partly and indirectly reflected through introducing parameterization of soil evaporation by linking it to soil moisture status as measured from microwave spectral bands, the latter has rather coarse spatial resolution even with the most advanced sensor such as SMOS (with $50 \mathrm{~km}$ pixel size and will be launched in late 2009), which is not sufficient to identify water variability over wetland areas both due to complex vegetation types and varying surface moisture status over space.

Different degrees of success in applying above mentioned methods over various land surface types are obtained in many applications, however very rare applications have been reported over wetland environments. Due to the heterogeneity of the vegetation types and of canopy density over the YRD wetland (specifically over the natural reserve areas), it becomes difficult to estimate the regional evapotranspiration by means of measurements done locally for a specific land cover type. Remote sensing can provide observations of land surface with high spatial and temporal resolution and coverage, monitoring of ET in the YRD wetland using the remote sensing technology is a very important contribution to scientific water resource management in the wetlands area.

Nevertheless, optical remote sensing measurements are often hampered by clouds coverage which leads to limited numbers of efficient data continuously available over a year. Researchers have made efforts in developing algorithms to generate cloud-free time series of, for instance, vegetation index for land surface vegetation monitoring purpose (Menenti et al., 1991, 1993; Verhoef et al., 1996; Roerink et al. 2000b; among others). The central idea is that a time series of irregularly spaced cloud-free observations can be modelled and reconstructed for each pixel independently using time series analysis. This avoids any requirement for full cloud-free images and maximizes the number of useful observations. Similar idea was adapted recently by others to estimate daily or yearly evapotranspiration by filling gaps in the geostationary or polar-orbited satellites optical observations (Jia et al., 2007; Daamen, 2008; Jia and Daanmen, 2009), which has shown promising perspectives in dealing with clouds contamination.
A model based on the Energy Balance was developed to estimate regional ET using observations of reflectance and land surface temperature from satellites (Menenti and Choudhury, 1993; Su, 2002). This model has been evaluated over many experimental areas with different land surface types (Jia et al., 2001, 2003; He et al., 2005; among others). In this study, we have used this method to calculate pixel-wise instantaneous evapotranspiration using instantaneous observations of land surface reflectance and temperature from MODIS (MODerate-resolution Imaging Spectroradiometer) when the data were available on clouds-free days. Daily values of ET were calculated based on the instantaneous ET values at each pixel assuming evaporative fraction remains constants over a clear day (Shuttleworth et al., 1989; Gurney and Hsu, 1990; Sugita and Brutsaert, 1991; Crago, 1996). A time series analysis algorithm, proposed by Verhoef (1996), was applied to generate a time series of daily ET over a yearly period by filling the gaps in the time series due to clouds. A detailed vegetation classification map produced from high spatial resolution SPOT image was used to help identifying areas of various wetland vegetation types and their spatial distribution over the YRD wetland. Such information was also used to improve the parameterizations of roughness length for momentum in the energy balance based model to improve the accuracy of ET estimates.

\section{Study area and data}

\subsection{Study area}

The study area of the YRD wetland was located in Dongying of Shandong province in China between the Bohai gulf and the Laizhou gulf, between $118^{\circ} 10^{\prime} \mathrm{E}$ and $119^{\circ} 15^{\prime} \mathrm{E}$, and $37^{\circ} 15^{\prime} \mathrm{N}$ and $38^{\circ} 10^{\prime} \mathrm{N}$. The administrative districts include Dongying district, Hekou district, Guangrao county, Lijin county and Kenli county. This region has prominent monsoon climate characterized as warm temperate zone with typical rainfall season in June, July and August. The wetland area covered by this study starts at Yuwa and ends at Tiaohekou in the north and Songchunrong river in the south. The total area is about $2400 \mathrm{~km}^{2}$ characterized by various wetland vegetation types, agricultural crops and other land cover types. Two nature reserve areas, currently recovering, were identified by the national nature reserve and protection program in recent years. One was named Northern Nature Reserve (NNR) area located in the north of the YRD with an area about $35 \mathrm{~km}^{2}$. The other one was named Southern Nature Reserve (SNR) area located in middle-east of the YRD with an area about $201 \mathrm{~km}^{2}$. 


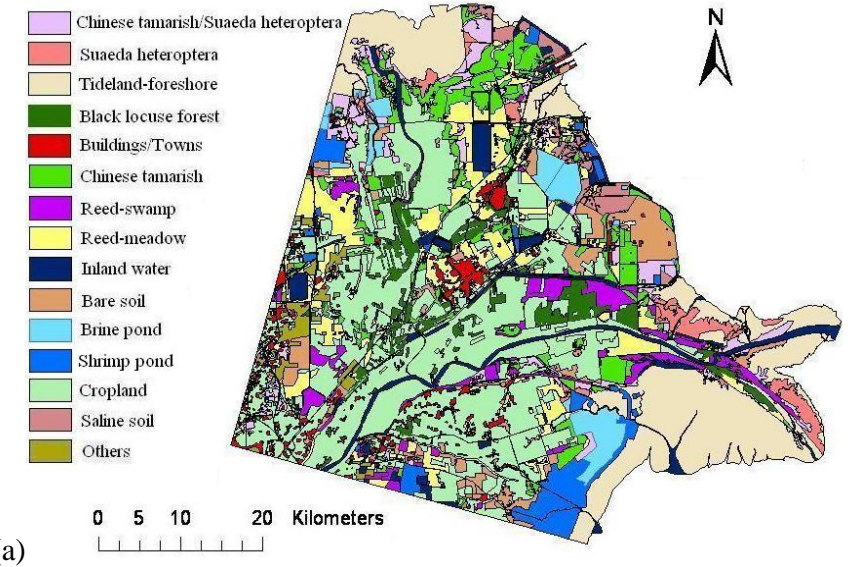

(a)

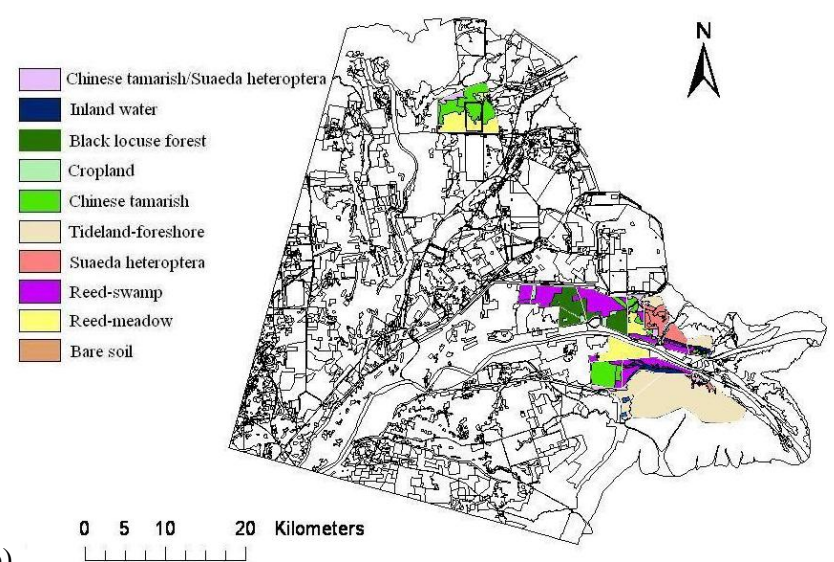

(b)

Fig. 1. (a) Land cover map of the YRD wetland; (b) vegetation classification of the NNR and the SNR areas of the YRD wetland.

\subsection{GIS and satellite remote sensing data}

\subsubsection{Land cover map}

A land cover map was generated based on one high spatial resolution (pixel size $2.5 \mathrm{~m} \times 2.5 \mathrm{~m}$ ) SPOT satellite image (see Cao et al., 2007 for details of the methodology for land cover classification). Intensive field survey was carried out in the summer of 2006 to collect geo-information and vegetation information in the YRD wetland area, which helped to have better classification of vegetation using the SPOT image. The land covers for the whole study area as well as for the NNR and NSR areas are shown in Fig. 1. The original very detailed vegetation classes were grouped into seven major vegetation classes and seven non-vegetation classes. Statistics of fractional area of each land surface/vegetation type in the whole wetland area and in the two natural reserve areas are given in Table 1. The high spatial resolution vegetation map was then re-sampled to $1 \mathrm{~km}$ resolution to match the pixel size of MODIS images used in the estimation of evapotranspiration by the surface energy balance model described in Sect. 3.
Table 1. Fractional areas of the seven major vegetation classes and seven non-vegetation land surface types in the whole YRD wetland and in the NNR and NSR areas (in percentage).

\begin{tabular}{lrrr}
\hline Classification & $\begin{array}{r}\text { Whole YRD } \\
\text { wetland (\%) }\end{array}$ & NNR (\%) & SNR (\%) \\
\hline Vegetation classes: & & & \\
Reed-swamp & 3.8 & - & 16.0 \\
Reed-meadow & 10.3 & 42.9 & 7.0 \\
Chinese tamarisk & 7.4 & 51.4 & 7.5 \\
Chinese tamarisk/ & 4.3 & 5.7 & 4.0 \\
Suaeda heteroptera & & & \\
Black Locust Forest & 2.7 & - & 10.4 \\
Suaeda heteroptera & 2.2 & - & 2.5 \\
Cropland & 30.1 & - & 10.9 \\
Non-vegetation classes: & & & \\
Tideland/Foreshore & 16.5 & - & 33.8 \\
Bare soil & 3.8 & - & 0.5 \\
Saline soil & 1.7 & - & - \\
Inland (open fresh) water & 4.3 & - & 5.0 \\
Shrimp pond & 3.8 & - & 1.5 \\
Brine pond & 3.0 & - & - \\
Buildings/Towns & 2.7 & - & - \\
Others & 1.6 & - & 1.0 \\
\hline
\end{tabular}

\subsubsection{MODIS data}

Land surface temperature, vegetation cover and land surface albedo were three essential surface variables in determining heat and water exchanges between land surface and the overlying atmosphere and the partitioning of available energy between soil and vegetation. We used data from MODIS for its optimal spectral bands, frequent re-visits and user-friendly data products. The utilized MODIS standard products in this study are listed in Table 2 which are available from the MODIS data distribution website (https://wist.echo.nasa. gov/wist-bin/api/ims.cgi?mode=MAINSRCH $\backslash \& J S=1$ ). Single band reflectance in each of the seven optical bands provided by MOD09A1 was converted to land surface albedo using the algorithm proposed by Liang (2000).

The MODIS land surface temperature data (MOD11A1) are daily products, while land surface reflectance (MOD09A1) and leaf area index (LAI) (MOD15A2) are 8-day composite data. Because land surface status defined by LAI and surface reflectance or surface albedo does not change significantly in short periods, 8-day interval is sufficient to describe the land surface properties.

\subsubsection{Meteorology data}

Meteorological data needed by the surface energy balance model to estimate evapotranspiration included wind speed, air temperature, humidity, air pressure, solar radiation, etc. In this study, these meteorological data at Dongying and Kenli meteorological stations were collected. Other data, like pan evaporation, precipitation, daily sunshine hours, daily cloud 
Table 2. The relevant MODIS standard products and land surface parameters.

\begin{tabular}{llll}
\hline MODIS standard products & Land surface parameter & Spatial resolution & Temporal resolution \\
\hline MOD09A1 & Land surface reflectance, & Bands 1-2: 250 m & 8 days \\
& NDVI & Bands 3-7: $500 \mathrm{~m}$ & \\
MOD11A1 & Land surface temperature & $1000 \mathrm{~m}$ & 1 day \\
MOD15A2 & Leaf area index (LAI) & $500 \mathrm{~m}$ & 8 days \\
\hline
\end{tabular}

cover were collected as well. There were two types of pans used in evaporation measurements, standard Class-A Evaporation Pan (model E601) and small pan with a diameter of $20 \mathrm{~cm}$. Pan size has influence on the evaporation from the pan, pan evaporation measured by small pan was therefore converted to the Class-A Evaporation Pan measurements by multiplying a conversion factor. The conversion factor was obtained by regressing daily evaporation measurements made by the two types of pans in a period between 1994 and 2000 when both measurements were available. The conversion factor was found to be 0.65 , i.e. ET $($ Pan_A $)=0.65$ ET (small pan).

\section{Methodology}

\subsection{Energy balance based model for evapotranspiration estimate}

The principle algorithm used for instantaneous ET estimate from remote sensing observations was the Surface Energy Balance System (SEBS), originally developed by Su (2002). Only a brief description is given in this paper, readers are referred to Menenti and Choudhury (1993), Su (2002) and Jia et al. (2003) for the details of the parameterization of the land surface energy balance, as applied in the model SEBS.

The surface energy balance is commonly written as

$R_{n}=G+H+\lambda E$

where $R_{n}$ is the net radiation $\left(\mathrm{W} \mathrm{m}^{-2}\right)$; $G$ is the soil surface heat flux $\left(\mathrm{W} \mathrm{m}^{-2}\right) ; H$ is the turbulent sensible heat flux $\left(\mathrm{W} \mathrm{m}^{-2}\right), \lambda E$ is the turbulent latent heat flux $\left(\mathrm{W} \mathrm{m}^{-2}\right)$ and $\lambda$ is the latent heat of vaporization $\left(\mathrm{J} \mathrm{kg}^{-1}\right)$. In Eq. (1) the energy for photosynthesis activity and other heat storage terms are considered relatively small and are therefore neglected.

The net radiation flux is the difference between downwards and upwards radiation fluxes at the land surface both in shortwave and longwave spectral domains, and is calculated by

$R_{n}=(1-\alpha) R_{\mathrm{swd}}+R_{\mathrm{lwd}}-\sigma \varepsilon_{s} T_{s}^{4}-\left(1-\varepsilon_{s}\right) R_{\mathrm{lwd}}$

where $\alpha$ is the land surface albedo (-), $R_{\mathrm{swd}}$ is the downward solar radiation flux $\left(\mathrm{W} \mathrm{m}^{-2}\right), R_{\text {lwd }}$ is the downward longwave radiation flux $\left(\mathrm{W} \mathrm{m}^{-2}\right), \varepsilon_{a}$ is the air emissivity
$(-), \varepsilon_{s}$ is the emissivity of the surface $(-), T_{s}$ is the surface temperature $(\mathrm{K}) ; \sigma$ is the Stefen-Bolzmann constant $\left(5.678 \times 10^{-8} \mathrm{~W} \mathrm{~m}^{-2} \mathrm{~K}^{-4}\right)$.

Soil surface heat flux is the heat flux into soil or water. Generally over land surface it is determined by a relationship with the net radiation flux as the following

$G=R_{n}\left[\Gamma_{c}+\left(1-f_{c}\right)\left(\Gamma_{s}-\Gamma_{c}\right)\right]$

where $\Gamma_{c}(-)$ and $\Gamma_{s}(-)$ are respectively the ratio of soil heat flux to net radiation for full vegetation canopy $\left(\Gamma_{c}=0.05\right.$, Monteith, 1973) and for bare soil $\left(\Gamma_{s}=0.315\right.$, Kustas and Daughtry, 1989). An interpolation is then performed between these limiting cases using the fractional canopy coverage $f_{c}$. The ratio was set as 0.5 for water surface where fractional vegetation cover was zero in this study.

Sensible heat flux is calculated using Monin-Obukhov Similarity (MOS) theory knowing atmospheric conditions and surface conditions. The atmospheric conditions are characterized by windspeed, air temperature and humidity at a reference height in the near surface layer or at the blending height of the atmospheric boundary layer. The surface conditions are characterized by surface or canopy roughness length both for momentum and for heat transfer, fractional vegetation coverage, land surface albedo and temperature. Equations are not given here for sensible heat flux calculation, instead we will give a brief description of the determination of some crucial surface parameters for sensible heat flux estimate for the YRD wetland in Sect. 3.2.

In SEBS, the actual sensible heat flux $H$ is constrained in the range set by the sensible heat flux at the wet limit $H_{\text {wet }}$ and the sensible heat flux at the dry limit $H_{\text {dry }}$. The two limits are defined as the following:

under the dry-limit, the latent heat (or the evaporation) would become zero due to the limitation of soil moisture and the sensible heat flux would be at its maximum value,

$H_{\text {dry }}=R_{n}-G_{0}$

Under the wet-limit, where the evaporation would take place at the potential rate, $\lambda E_{\text {wet }}$, i.e. the evaporation would be limited only by the energy available under the given surface and atmospheric conditions, the sensible heat flux would take its minimum value, $H_{\text {wet }}$, i.e.: 
$\lambda E_{\mathrm{wet}}=R_{n}-G_{0}-H_{\mathrm{wet}}$

or

$H_{\mathrm{wet}}=R_{n}-G_{0}-\lambda E_{\mathrm{wet}}$

The relative evaporation is defined as the ratio of actual evapotranspiration to its wet extreme as

$\Lambda_{r}=\frac{\lambda E}{\lambda E_{\mathrm{wet}}}=1-\frac{\lambda E_{\mathrm{wet}}-\lambda E}{\lambda E_{\mathrm{wet}}}$

or is expressed by sensible heat flux and its extremes as

$\Lambda_{r}=1-\frac{H_{\text {dry }}-H}{H_{\text {dry }}-H_{\text {wet }}}$

The evaporative fraction, $\Lambda$, i.e. the energy used for the evaporation process divided by the total amount of available energy, is calculated by

$\Lambda=\frac{\lambda E}{R_{n}-G}=\frac{\Lambda_{r} \cdot \lambda E_{\mathrm{wet}}}{R_{n}-G}$

By inverting Eq. (9), the actual latent heat flux $\lambda E$ can be obtained. Latent heat flux $\lambda E$ is then converted to water depth in mm per time unit, say $\operatorname{ET}=(\lambda E) /\left(\lambda \rho_{w}\right)$, where $\rho_{w}$ is the density of water $\left(\mathrm{kg} \mathrm{m}^{-3}\right)$.

\subsection{Determination of roughness length}

Among the parameters needed by the SEBS model, roughness length of the land surface for momentum transfer $\left(z_{0 \mathrm{~m}}\right)$ is the most crucial one, which determines the height of momentum exchange between the land surface and the atmosphere as well as the source/sink height of heat and water in the land surface and the atmosphere interaction through the factor $\mathrm{kB}^{-1}\left(=\ln \left(z_{0 \mathrm{~m}} / z_{0 \mathrm{~h}}\right)\right.$, where $z_{0 \mathrm{~h}}$ is the roughness length of the land surface for heat transfer) (Brutsaert, 1982 among others). Physically detailed models have been developed to estimate roughness length for momentum with consideration of canopy structure (Raupach, 1992, 1994; Massman, 1997), difficulties are encountered due to the lack of detailed information of canopy structure and canopy aerodynamic properties needed by the models for regional scale application. Remote sensing measurement of canopy structure made by laser altimeter is suitable to estimate effective roughness length of a heterogeneous land surface (Menenti and Ritchie, 1994). Such measurements, however, were not available over the experimental sites used in this study. In many remote sensing models for ET estimate over regional scale, estimation of $z_{0 \mathrm{~m}}$ is often related to NDVI, which can be derived from remote sensing observation. However, both the density and height of surface canopy have influence on the roughness length, while NDVI can only partly reflect the density of vegetation canopy. In this study we have considered the two factors, say the density and the height of a vegetation canopy through the vegetation map together with vegetation growth information provided by LAI and the canopy height collected in the field survey over the various vegetation canopies in the YRD wetland in different seasons. The equations used to estimate $z_{0 \mathrm{~m}}$ for short canopies were taken from Zhang (1996) in which $z_{0 \mathrm{~m}}$ is a function of canopy height and LAI. For forest, water, bare soil, and resident area, $z_{0 \mathrm{~m}}$ values were taken as $0.5 \mathrm{~m}, 0.0005 \mathrm{~m}, 0.001 \mathrm{~m}$ and $0.5 \mathrm{~m}$, respectively (Brutsaert, 1982; Basstiaanssen et al., 1998b; Gao et al., 2002).

\subsection{Total daily ET}

Since all the terms in the energy balance equation (Eq. 1) were estimated using instantaneous observations by MODIS, the calculated instantaneous ET (unit $\mathrm{mm} \mathrm{s}^{-1}$ ) must be integrated to obtain a daily total ET (unit $\mathrm{mm} \mathrm{d}^{-1}$ ) by the summation of the instantaneous ET values over $24 \mathrm{~h}$. This was based on the assumption that evaporative fraction remains constant approximately though the sensible and latent heat fluxes may fluctuate strongly during a day (Sugita and Brutsaert, 1991). This leaded to the equation for the total daily ET as

$$
\begin{aligned}
& \mathrm{ET}_{\text {daily }}=\sum_{i=0}^{24}\left[\Lambda \cdot \frac{R_{n}-G}{\lambda \rho_{w}}\right]_{i} \\
& =24 \text { (hours) } \times 3600 \text { (seconds) } \times\left[\Lambda \cdot \frac{\mathrm{R}_{\text {ndaily }}-\mathrm{G}_{\text {daily }}}{\lambda \rho_{\mathrm{w}}}\right]\left(\mathrm{m} \mathrm{d}^{-1}\right) \\
& =8.64 \times 10^{7} \cdot\left[\Lambda \cdot \frac{R_{\text {ndaily }}-G_{\text {daily }}}{\lambda \rho_{w}}\right]\left(\mathrm{mm} \mathrm{d}^{-1}\right)
\end{aligned}
$$

where $R_{\text {ndaily }}$ is the daily mean net radiation, $G_{\text {daily }}$ is the daily mean soil surface heat flux, $\rho_{w}$ is the density of water $\left(\mathrm{kg} \mathrm{m}^{-3}\right) ; \lambda$ is the latent heat of water taken as $2.47 \times 10^{6}$ $\left(\mathrm{J} \mathrm{kg}^{-1}\right)$. For a clear day, the daily average soil heat flux cancels out as positive fluxes occur during night and negative during daytime.

\subsection{Monthly and annual ET by gap-filling method}

Satellite-based methods using optical remote sensing obsverations to estimate evapotranspiration often encounter the problem of clouds contamination so that the number of usable observations at any given location (pixel) during a year cycle is limited. To fill the gaps in the missing observations due to clouds for each pixel, a time series analysis algorithm Harmonic ANalysis of Time Series (HANTS) (Verhoef, 1996; Roerink et al., 2000b) was used to generate gapfilled daily time series of ET for each pixel over a year. The algorithm involved in HANTS allows the use of irregularly spaced observations over a certain period and allows the user to choose the frequencies of the periodic functions used to model the observed time series. As such, it is possible to follow to a certain extent the fluctuations of the water exchange between the land surface and the atmosphere due to changes in weather and surface moisture conditions. 
Finally, monthly and annual ET were calculated by the summation of the gap-filled daily ET values over each month and over each year period, respectively.

\section{Results and discussions}

\subsection{Method evaluation}

\subsubsection{Evaluation of the modeled evapotranspiration}

Since there were no direct measurements of latent heat flux or actual evapotranspiration over the YRD wetland in 2005, we proposed an alternative method to evaluate the calculated ET. The principle of the evaluation was based on the assumption that evapotranspiration of wet vegetated surfaces should be very close to the reference evapotranspiration (denoted as $\left.\mathrm{ET}_{\text {ref }}\right)$ derived from FAO56 Penman - Monteith equation (Allen et al., 1998). In the YRD wetlands the ideal wet vegetated targets are "reed swamp" and "Suaeda heteroptera". However, soil water conditions might vary due to the variation of water flow to the wetland or of the precipitation for a certain period, "reed swamp" or "Suaeda heteroptera" might not be all the time under water unlimited condition. To select pixels which were under wet conditions, pixels with "reed swamp" standing perennially in water and pixels with "Suaeda heteroptera" near to the inter-tidal areas were identified first by checking the vegetation classification map as shown in Fig. 1. As the second step, land surface temperature of pixels classed as "reed swamp" and "Suaeda heteroptera" selected in the preliminary check was plotted against albedo of the same pixels. Completely wet pixels were identified by both their lower LST and lower albedo (figure is not shown), there were four "reed swamp" pixels and five "Suaeda heteroptera" pixels respectively that fell in the categories mentioned above. The evaluation of the model estimated evapotranspiration was done using these nine wet targeting pixels. Comparing the actual daily ET values in these wet pixels with the $\mathrm{ET}_{\text {ref }}$ values derived on clear sky days in 2005 showed an acceptable agreement with the Root Mean Square Error (RMSE) of $0.88 \mathrm{~mm}$ and $1.3 \mathrm{~mm}$ for "Suaeda heteroptera" and "reed swamp", respectively. One should keep in mind that such comparison can only be taken as very preliminary evaluation on the model performance, more careful validation should be carried out using field experiments if there would be any available.

\subsubsection{Gap-filled ET on cloudy-days by time series anal- ysis}

The time series analysis algorithm HANTS was used to fill the gaps in the modeled evapotranspiration. After preliminary cloud check on the MODIS images, 153 images in 2005 were selected as quasi cloud-free images though there might still be some pixels contaminated by clouds in the images on different days. The estimated daily ET maps using MODIS observations on the 153 quasi cloud-free days were taken as the basic dataset to reconstruct the time series of daily ET in 2005 by applying HANTS to it.

Figure 2 showed the examples, for one pixel of wet "reed swamp", of the time series of daily ET values in 2005 estimated by the SEBS model and the gap-filled ET values using the HANTS. The reference ET estimated by the FAO56 equation $\left(\mathrm{ET}_{\text {ref }}\right)$ was also given in Fig. 2. The gap-filled curve of the modeled ET have followed the $\mathrm{ET}_{\text {ref }}$ during the year cycle, though the absolute magnitudes were not exactly the same, indicating that the algorithm HANTS was efficient to re-produce the time series of ET values with acceptable errors. Outliers, defined as such that estimated ET was far below the gap-filled curve, were supposed to be from cloudy pixels or days. It appeared that the frequency and duration of the gaps were limited and not sufficient to degrade the information on the temporal evolution of vegetation cover and surface temperature contained in the irregularly spaced observations retained after pixel-wise clouds screening over the YRD wetland in 2005.

To have a better comparison, a smaller dataset was made out of the 153 quasi-clouds-free images by meeting the criterion that "daily amount of clouds measured at Dong Ying meteorological station is zero". There were 67 days that meet this criterion in the year 2005. Figure 3 showed the values of the estimated ET by SEBS, the gap-filled ET by HANTS, the reference ET and the measurements of pan evaporation on the 67 clouds-free days for the same pixel of wet "reed swamp" as in Fig. 2.

\subsubsection{Relationship between vegetation potential ET and reference $\mathrm{ET}$}

In many agricultural and hydrological practices, the actual ET of a vegetation canopy (denoted as $\mathrm{ET}_{\text {act }}$ ) is commonly calculated from ET value of a reference crop, i.e. reference ET as mentioned earlier, by multiplying a "crop coefficient" $K_{c}$ (or "cover" coefficient in general for any land cover type in particular vegetation) (Doorenbos and Pruitt, 1977; Allen et al., 1998):

$\mathrm{ET}_{\mathrm{act}}=K_{c} \mathrm{ET}_{\mathrm{ref}}$

While such approach is very practical to use once the seasonal average $K_{c}$ is defined for the crop or cover type of interest, the disadvantage of using crop or cover coefficient approach for the vegetation ET calculation is that it is difficult to quantify the changes in $K_{c}$ given a change in the height, the vegetation density (both in LAI and spacing) and the stomatal resistance of a plant as indicated by Allen et al. (1994). Such changes are often significant in wetland vegetation over space due to the complex nature of wetland, i.e. the size, vegetation classes, surface and ground water conditions, etc. A large range of $K_{c}$ values for different types of wetland plants and plant communities was observed (see reviews by Drexler et al., 2004 and Fermor et al., 2001, among 


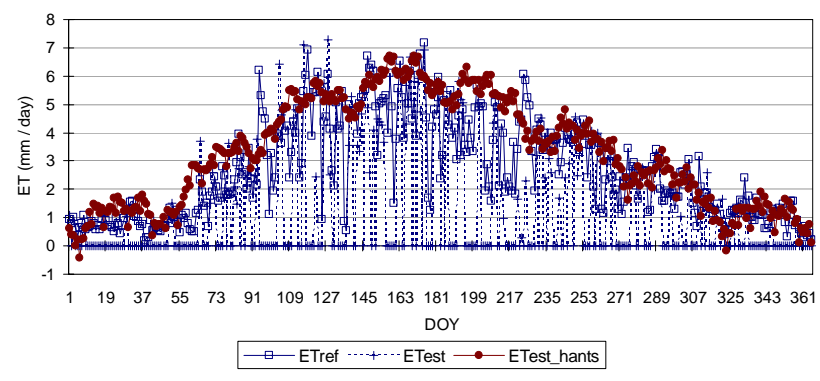

Fig. 2. Time series of the estimated daily ET in 2005 (ETest, “+”) and the gap-filled daily ET (ETest_hants, "•") in one pixel of "reedswamp" class. ET ref is given as a reference (“ $\square$ ”).

others). We will evaluate the $K_{c}$ approach for the two hydrophytes in the YRD wetland, i.e. the "reed swamp" and "Suaeda heteroptera", based on the modeled time series of pixel-wise $K_{c}$ values.

The analysis on the regression between the estimated ET of reed-swamp and Suaeda heteroptera and the $\mathrm{ET}_{\text {ref }}$ are shown in Table 3. The modeled actual ET values in Table 3 are the average over all the pixels of each class of the two wetland hydrophytes respectively for each of the 67 cloudsfree days. When the regression is forced through the origin, the slope of the regression line can be interpreted as the bulk "crop" or "cover" coefficient for the corresponding "crop" or vegetation cover.

Different slopes were found in different growing seasons (Table 3) for each of the two wetland vegetation types. Changes in the slope in different seasons were likely due to, among others, changes in leaf area index. Such changes in LAI were significant in the growing season when leaf area was increasing dramatically (April to June). However, an obvious phase shift was observed between the daily ET and the vegetation growth presented by LAI over the year of 2005 (Fig. 3), the peak of the daily ET appeared earlier than the one of LAI. Weather condition was a possible cause of the phase shift between daily ET and LAI. Based on the analysis on the meteorological data from the nearby meteorological stations July and August were in rainfall season in the YRD wetland. Heavy rainfall and low solar radiation might have resulted in low ET due to too high atmospheric moisture and too low available energy for evapotranspiration. This implies that inclusion of LAI only in the $K_{c}$ calculation may be not sufficient to improve the accuracy of ET estimate by the $K_{c}$ approach.

Further analysis showed that the spatial variability, characterized by the range between the maximum and the minimum values of the same vegetation type of the wetland on the same day, was significantly large over the same vegetation type (Fig. 4). Such large spatial variability might be caused by several factors, e.g. large spatial heterogeneity in vegetation density and height, spatial variation in soil water content or the depth of surface water under the plants, solar

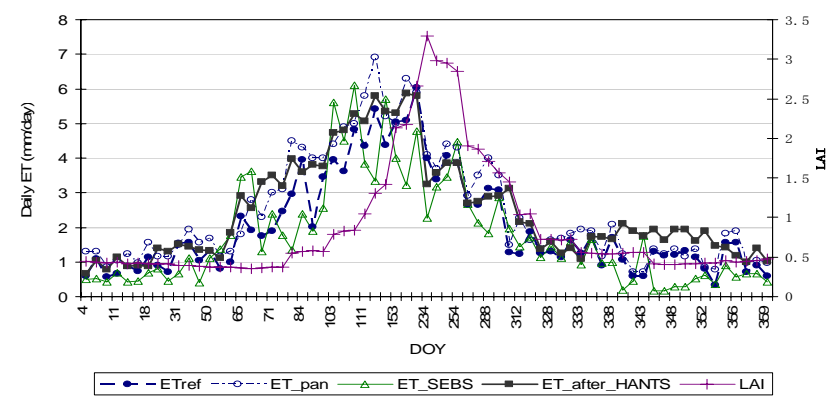

Fig. 3. Comparison between the estimated daily ET, the gap-filled daily ET, the reference ET and pan evaporation measurements in Dongying meteorological station over "clouds-free" days in 2005.
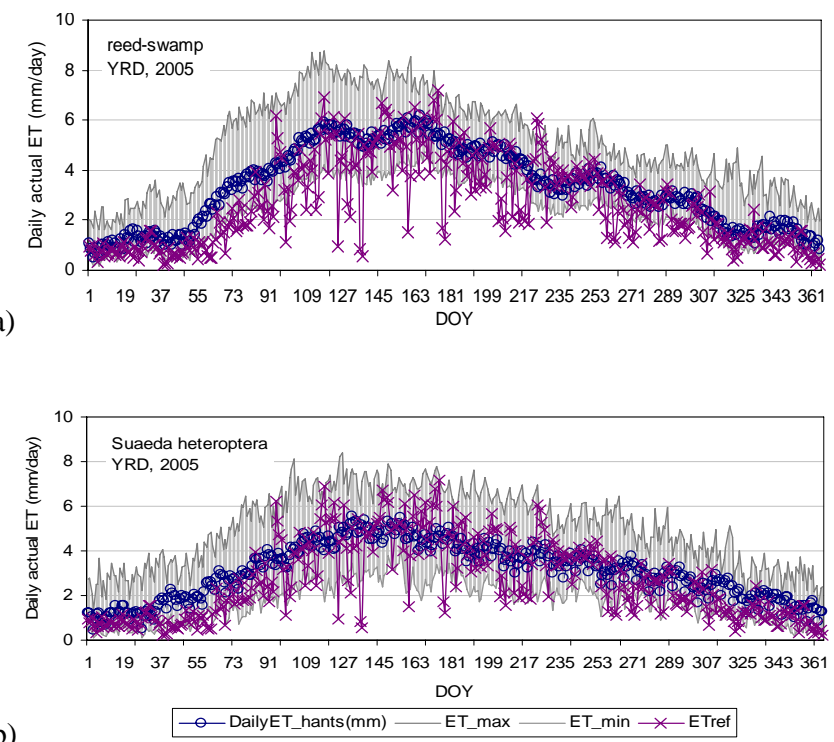

Fig. 4. The gap-filled daily ET averaged over all pixels corresponding to two vegetation types: (a) reed-swamp; and (b) Suaeda heteroptera over the YRD wetland in 2005. Spatial variability is represented by the difference between the maximum and minimum values of the same vegetation type of each day (shaded areas).

radiation variability in space, variation of ground water table in the wetland, etc. As the consequence, simple empirical relationship as defined by a constant "crop coefficient" for each crop (or in general each vegetation type) in each growing season may be not appropriate for the ET calculation of the wetland vegetation canopies.

\subsection{Seasonality and spatial heterogeneity of ET in the YRD wetland}

Evapotranspiration in the YRD wetland showed strong seasonality as illustrated by the integrated monthly ET maps over April-May-June and over July-August-September (Fig. 5). Along the course of the year 2005, monthly evapotranspiration followed the regular variations in annual 
Table 3. Regressions between estimated ET and reference ET over "reed-swamp" and "Suaeda heteroptera" on clouds-free days in 2005 in the YRD wetland.

\begin{tabular}{lllll}
\hline & \multicolumn{2}{c}{ Reed-swamp } & \multicolumn{2}{c}{ Suaeda heteroptera } \\
\cline { 2 - 5 } & $\mathrm{ET}_{\text {est }} / \mathrm{ET}_{\text {ref }}$ & Correlation coefficient, $R$ & $\mathrm{ET}_{\text {est }} / \mathrm{ET}_{\text {ref }}$ & Correlation coefficient, $R$ \\
\hline Jan-Mar & 1.1193 & 0.88 & 1.1775 & 0.89 \\
Apr-Jun & 1.0173 & 0.84 & 0.9039 & 0.28 \\
Jul-Sep & 0.9262 & 0.80 & 0.9531 & 0.34 \\
Oct-Dec & 1.1113 & 0.66 & 1.2604 & 0.72 \\
Whole year & 1.0308 & 0.93 & 1.0224 & 0.91 \\
\hline
\end{tabular}

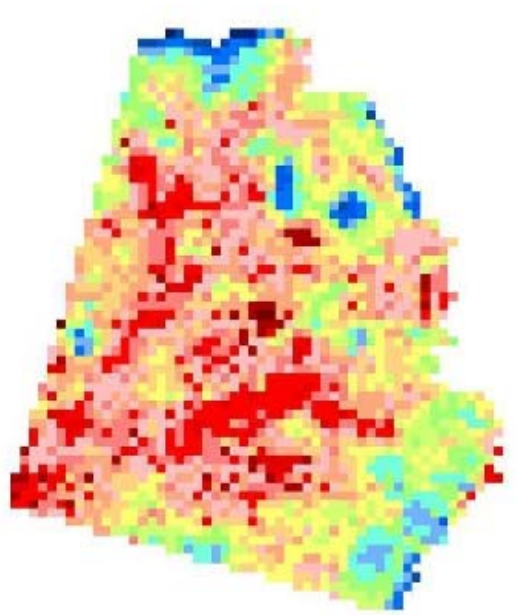

(a) Apr-May-June

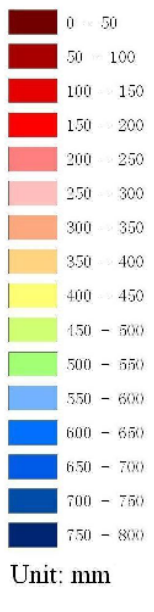

(b)

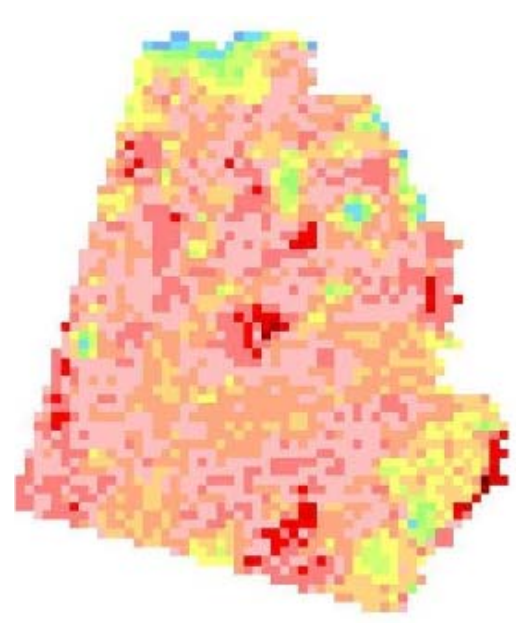

July-Aug-Sep

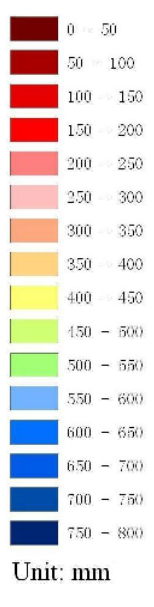

Fig. 5. Maps of ET estimates integrated over (a) April-May-June; (b) July-August-September in the YRD wetland in 2005.

meteorological conditions and vegetation growing seasons. As a consequence, larger values appeared in May, June and July with the peak of evapotranspiration about $130 \mathrm{~mm}$ in June (Fig. 6).

In contrast to the winter months January-February and November-December, ET spatial patterns vary dramatically over the entire wetland in the growing seasons, particularly during April, May and June (Fig. 5). Crops and grasslands were at the beginning stage of growth in April and May with lower LAI. The major contributor to the total ET in the drylands (including croplands, grassland, Black Locust Forest, and Chinese tamarisk) was soil. With insufficient rainfall in April and May, cropland might have lower soil water moisture comparing to the swamp areas. The ET distribution in turn showed smaller values in the drylands, while increasing in steps to swampland vegetations with wetter soil (e.g. reed-meadow), swampland vegetations in the standing water (e.g. reed-swamp and Suaeda heteroptera) and inter-tidal zones which might be flooded by seawater or fresh water.
In June and July, ET difference between the dryland and swampland vegetations was less significant (monthly ET maps were not shown here). Vegetations in the dryland areas had developed during this period, implying that transpiration from well developed green plants was the major contributor to the total ET in the dryland areas. Moreover, sufficient rainfall encountered in June and July ensured soil in an optimal moisture condition both in the dryland and the swampland areas. However, differences still existed between vegetated areas and tideland.

In September LAI values of most vegetation species started decreasing due to senescence of leaves, which resulted in sharp decreases in vegetation transpiration, except for the vegetations standing in water.

During the winter months, i.e. January/February and November/December, ET from the entire wetland area was quite uniform (maps were not shown). 


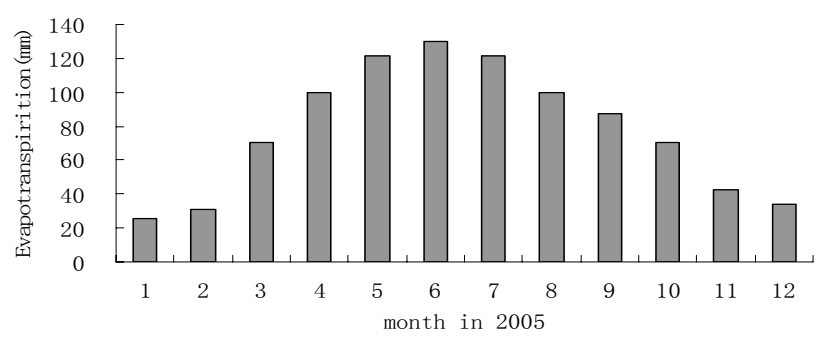

Fig. 6. Statistics of monthly ET in the YRD wetland in 2005.

\subsection{Annual ET and wetland water requirements}

\subsubsection{The whole YRD wetland}

Figure 7 gives the spatial distribution of the annual ET in 2005 over the YRD wetland. The annual evapotranspiration in 2005 over the whole study area of the YRD wetland was $947 \mathrm{~mm}$ with a standard deviation of $302 \mathrm{~mm}$. Such large standard deviation in the estimated ET attributed to the large variation of ET among different land cover classes over the whole study area. Ranges of evapotranspiration were found between $470 \mathrm{~mm}$ on average observed in the class of towns and buildings and about $1400 \mathrm{~mm}$ on average in the tideland/foreshore areas along the coast and in the class of inland open water surfaces (Fig. 7). The spatial distribution of evapotranspiration of various vegetations also showed large heterogeneity as expected, particularly among dryland vegetation (e.g. croplands) and swampland vegetations in standing water (e.g. reed-swamp). Mean annual ET values of all major vegetations are listed in Table 4.

The areas of the land cover classes and the corresponding amount of water used for evaporation or evapotranspiration are also given in Table 4. Among the vegetation classes, two wetland vegetations often standing in water, reed-swamp and Suaeda heteroptera, had the largest annual ET on average. The reed-swamp and reed-meadow had very close annual ET indicating that transpiration from plants was higher than that from the interspersed water. Likely, water table was high enough for reed-meadow to pump ground water for transpiration, but this should be investigated in further studies.

Salty water bodies seemed evaporating much more than open fresh water bodies in the YRD area in 2005.

The total amount of water evaporated by water bodies and bare lands and evapotranspiration from vegetation-soil or vegetation-water canopies of the whole wetland area of about 277100 hectares $\left(2771 \mathrm{~km}^{2}\right)$ in 2005 was about $27 \times 10^{8} \mathrm{~m}^{3}$. The estimated range of annual ET, given in the rightmost column of Table 4, was calculated from the standard deviation of the pixel-wise ET values and it implied the assumption that ET was either maximum or minimum for all pixels (in any land cover type) at the same time. In other words it was very unlikely that such a large range would be observed in practice. Since the value of $27 \times 10^{8} \mathrm{~m}^{3}$ was the actual ET

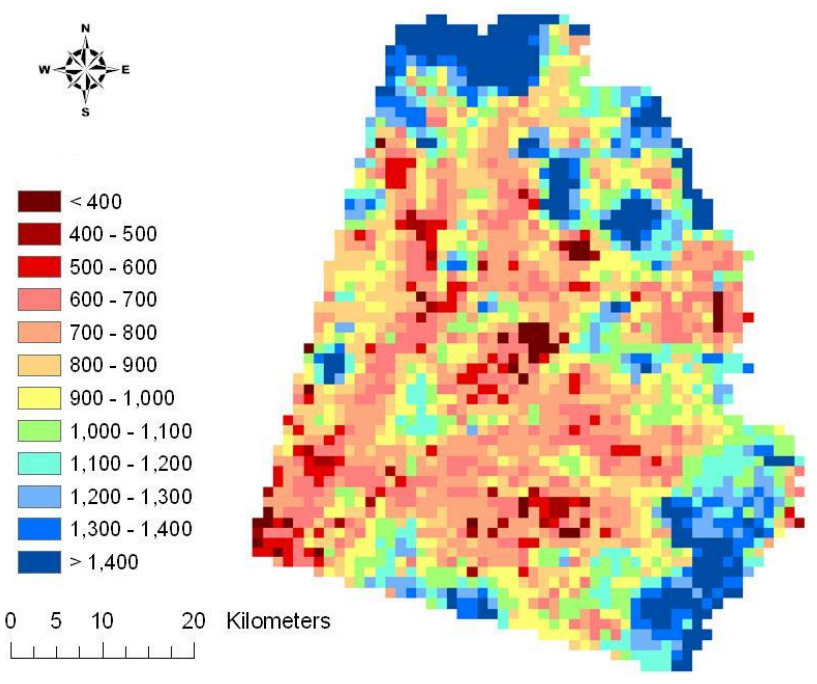

Fig. 7. The spatial distribution of annual ET in the YRD wetland in 2005 (unit: $\mathrm{mm}$ ).

from the area, it can be considered as the water requirement by the wetland system for vegetation growth and water loss due to evaporation process to remain in its current conditions in 2005.

The total water needed by vegetation canopies in 2005 in the YRD wetland was about $5.27 \times 10^{8} \mathrm{~m}^{3}$, of which about $4.59 \times 10^{8} \mathrm{~m}^{3}$ were consumed by natural wetland vegetations with an areas about 89400 hectares $\left(894 \mathrm{~km}^{2}\right)$.

\subsubsection{Annual ET in the natural reserve areas}

One of the objectives of this study was to provide an estimate of how much water was needed by the two nature reserve areas in the YRD wetland, i.e. the NNR and the SNR. Such information is important both for the water authority and the Nature Reserve society.

During the period of this study, the NNR was defined as 3500 hectares $\left(35 \mathrm{~km}^{2}\right)$ and had only three major types of wetland vegetations (many more vegetation types and species with very small and scattered areas were grouped into these three major classes). The annual total water consumed by these naturally vegetated surfaces in the NNR in 2005 was about $0.318 \times 10^{8} \mathrm{~m}^{3}$ (Table 5).

In the definition of the two natural reserve areas when this study was carried out, the SNR was much larger than the NNR and having more vegetation types than the NNR (Fig. 1). The total actual evapotranspiration from the SNR in 2005 was about $2.264 \times 10^{8} \mathrm{~m}^{3}$ (Table 6). Reed-swamp and reed-meadow among others were the major wetland vegetations to be protected and areas of reed-swamp and reedmeadow would be extended by replacing cropland in the future to recover the SNR wetland area for the purpose of protecting the diversity of wetland birds. In 2005, water consumed by reed beds (including reed-swamp and reed- 
Table 4. Annual ET and water requirements in the YRD wetland in 2005. ET_range denotes the standard deviation over space among the same class.

\begin{tabular}{lrrrrr}
\hline Whole wetland & $\begin{array}{r}\text { Areas } \\
\left(\mathrm{km}^{2}\right)\end{array}$ & $\begin{array}{r}\text { ET } \\
(\mathrm{mm} / \text { year })\end{array}$ & $\begin{array}{r}\text { ET_std } \\
(\mathrm{mm} / \text { year })\end{array}$ & $\begin{array}{r}\text { ET } \\
\left(10^{8} \mathrm{~m}^{3}\right)\end{array}$ & $\begin{array}{r}\text { ET_range }( \pm) \\
\left(10^{8} \mathrm{~m}^{3}\right)\end{array}$ \\
\hline Reed-swamp & 99 & 1036.6 & 195.3 & 1.026 & 0.193 \\
Reed-meadow & 315 & 934.2 & 171.1 & 2.943 & 0.539 \\
Chinese tamarisk & 198 & 822.8 & 197.3 & 1.629 & 0.391 \\
Chinese tamarisk/Suaeda heteroptera & 127 & 889.1 & 215.7 & 1.129 & 0.274 \\
Black Locust Forest & 102 & 773.4 & 174.2 & 0.789 & 0.178 \\
Suaeda heteroptera & 53 & 1099.4 & 236.4 & 0.583 & 0.125 \\
Cropland & 825 & 833.8 & 164.8 & 6.879 & 1.360 \\
Tideland/Foreshore & 455 & 1433.8 & 291.0 & 6.524 & 1.324 \\
Bare soil & 107 & 716.6 & 206.1 & 0.767 & 0.221 \\
Saline soil & 46 & 910.2 & 271.7 & 0.419 & 0.125 \\
Inland (open fresh) water & 138 & 1188.6 & 299.1 & 1.640 & 0.413 \\
Shrimp pond & 96 & 1273.0 & 170.8 & 1.222 & 0.164 \\
Brine pond & 84 & 1332.2 & 221.0 & 1.119 & 0.186 \\
Buildings/Towns & 82 & 470.2 & 187.8 & 0.386 & 0.154 \\
Others & 44 & 858.9 & 158.3 & 0.378 & 0.070 \\
Total & & & & 27.432 & \\
\hline
\end{tabular}

Table 5. Annual ET in the NNR area of the YRD wetland in 2005. ET_range denotes the standard deviation over space among the same class.

\begin{tabular}{lrrrrr}
\hline Northern NR & $\begin{array}{r}\text { Areas } \\
\left(\mathrm{km}^{2}\right)\end{array}$ & $\begin{array}{r}\text { ET } \\
(\mathrm{mm} / \text { year })\end{array}$ & $\begin{array}{r}\text { ET_std } \\
(\mathrm{mm} / \mathrm{year})\end{array}$ & $\begin{array}{r}\text { ET } \\
\left(10^{8} \mathrm{~m}^{3}\right)\end{array}$ & $\begin{array}{r}\text { ET_range }( \pm) \\
\left(10^{8} \mathrm{~m}^{3}\right)\end{array}$ \\
\hline Reed-meadow & 15 & 1024.5 & 247.0 & 0.154 & 0.037 \\
Chinese tamarisk & 18 & 833.9 & 90.0 & 0.150 & 0.016 \\
Chinese tamarisk/Suaeda heteroptera & 2 & 727.2 & 105.2 & 0.015 & 0.002 \\
Total & 35 & & & 0.318 & \\
\hline
\end{tabular}

meadow)_in the SNR was about $0.5 \times 10^{8} \mathrm{~m}^{3}$. Under the similar meteorological conditions as in 2005 , one can estimate how much water would be evaporated in a year by the perspective reed beds assuming all or part of current croplands would be replaced by reed beds. By analyzing the monthly actual evapotranspiration from each vegetation type, water supply planning can be scheduled according to the water needs in the growing seasons of the major vegetation types in the nature reserve area.

The water consumed by the wetland vegetation as estimated above (Table 4) can be used as the reference for water supply to the national reserve areas, while annual fluctuations will be within the range indicated in Table 4 for each land cover class.

\section{Conclusions}

Through this study, the following conclusions were drawn:

- Evapotranspiration over the YRD wetland was estimated using remote sensing observations of land surface parameters. The calculation was first done using instantaneous MODIS observations by taking into account the detailed vegetation classifications to improve the parameterizations in the model used. Daily values of evapotranspiration were obtained by integrating the instantaneous values assuming a constant evaporative fraction during daytime. Comparison of the estimated daily ET over wet targets showed consistent trends with the reference ET values from the FAO56 formula using meteorological measurements indicating that the model performance in simulating daily ET was acceptable. A method using Fourier transform was proposed to fill the gaps in ET estimate on cloudy days when the satellite 
Table 6. Annual ET in the SNR area of the YRD wetland in 2005. ET_range denotes the standard deviation over space among the same class.

\begin{tabular}{lrrrrr}
\hline Southern NR & $\begin{array}{r}\text { Areas } \\
\left(\mathrm{km}^{2}\right)\end{array}$ & $\begin{array}{r}\text { ET } \\
(\mathrm{mm} / \text { year })\end{array}$ & $\begin{array}{r}\text { ET_std } \\
(\mathrm{mm} / \text { year })\end{array}$ & $\begin{array}{r}\text { ET } \\
\left(10^{8} \mathrm{~m}^{3}\right)\end{array}$ & $\begin{array}{r}\text { ET_range }( \pm) \\
\left(10^{8} \mathrm{~m}^{3}\right)\end{array}$ \\
\hline Reed-swamp & 32 & 1131.3 & 129.8 & 0.362 & 0.042 \\
Reed-meadow & 14 & 982.6 & 79.4 & 0.138 & 0.011 \\
Chinese tamarisk & 15 & 1019.0 & 135.3 & 0.153 & 0.020 \\
Chinese tamarisk/Suaeda heteroptera & 8 & 1018.1 & 142.0 & 0.081 & 0.011 \\
Suaeda heteroptera & 5 & 1099.4 & 0.0 & 0.055 & 0.000 \\
Black Locust Forest & 23 & 950.6 & 182.2 & 0.219 & 0.042 \\
Cropland & 22 & 986.7 & 153.1 & 0.217 & 0.034 \\
Tideland/Foreshore & 68 & 1295.1 & 210.3 & 0.881 & 0.143 \\
Bare soil & 1 & 716.6 & 0.0 & 0.007 & 0.000 \\
Inland(open) water & 10 & 1167.8 & 41.2 & 0.117 & 0.004 \\
Shrimp pond & 3 & 1153.6 & 146.1 & 0.035 & 0.004 \\
Total & 201 & & & 2.264 & \\
\hline
\end{tabular}

observations, in particular the land surface temperatures, were not available. Though the method needs to be carefully evaluated using in-situ measurements of land surface fluxes or actual evapotranspiration in the wetland, the comparison between the trends in the time series of the gap-filled daily ET over wet targets during the year 2005 and the reference ET from the FAO56 using meteorological data showed good consistency. The gap-filled daily ET might still be with relatively larger errors, while the monthly and yearly values of ET were expected to achieve good accuracy, since random errors were smoothed by time series modeling.

- In the YRD wetland area, spatial variability in daily, monthly and annual ET was significant due to various wetland vegetation types, their heterogeneity in space and in different growing seasons, as well as variation in soil water content. Seasonal variation in the ET of the YRD wetland was very significant and varying among different vegetations, which leaded to the fact that water requirement by different wetland vegetations and agricultural crops were changing with vegetation phenology and the wetland weather conditions.

- Classical "crop coefficient" method may not be suitable for wetland ET estimates due to the complications of land surface properties characterized both by various wetland vegetation types and by varying soil water content over the YRD wetland. Method for regional ET estimates using remote sensing observation as demonstrated in this study is a promising and powerful tool for wetland ET monitoring.

- Further study should focus on detailed analysis on the relationship between ET from different vegetations and ground water table and vegetation conditions (e.g. LAI).
To do the latter remote sensing images with higher spatial resolution will be needed. Moreover, careful evaluation of the parameterizations, in particular for soil heat flux and roughness length, and of the method used for gap-filling should be in the consideration in the further study.

Acknowledgements. This work was supported jointly by the CAS projects (KZCX2-YW-Q10-2 and "Talent Project"), the European Commission as part of the CEOP - AEGIS project (Call FP7ENV-2007-1 Grant no. 212921) (http://www.ceop-aegis.org/), the Sino-Dutch cooperative project "Yellow River Delta Environment Flow" and the Hi-tech Research and Development Program of China (2007AA12Z175). The authors thank to the three reviewers for their constructive comments and suggestions that have helped to shape the final version of this paper.

Edited by: Z. Su

\section{References}

Allen, R. G., Pereira, L. S., Raes, D., and Smith, M.: Crop Evapotranspiration, Guideline for Computing Crop Water Requirements, FAO Irrigation and Drainage Paper 56, FAO Rome, Italy, 300 pp., 1998.

Allen, R. G., Smith, M., Pereira, L. S., and Perrier, A.: An update for the calculation of reference evaporation, ICID Bulletin, 43, 35-92, 1994.

Bastiaanssen, W. G. M., Menenti, M., Feddes, R. A., and Holtslag, A. A. M.: A remote sensing surface energy balance algorithm for land (SEBAL) 1. Formulation, J. Hydrol., 212-213, 198-212, 1998a.

Bastiaanssen, W. G. M., Pelgrum, H., Wang, J., Ma, Y., Moreno, J. F., Roerink, G. J., and van der Wal, T.: A remote sensing surface energy balance algorithm for land (SEBAL) 2. Validation, J. Hydrol., 213, 213-229, 1998b. 
Brutsaert, W. H.: Evaporation into the Atmosphere: Theory, History, and Applications, Reidel, Dordrecht, The Netherlands, 299 pp., 1982.

Cao, M., Liu, G., and Zhang, X.: An object-oriented approach to map wetland vegetation: a case study of yellow river delta, IEEE International Geoscience and Remote Sensing Symposium, 2007 (IGARSS 2007), 23-28 July 2007, 4585-4587, 2007.

Cleugh, H. A., Leuning, R., Mu, Q.-Z., and Running, S. W.: Regional evaporation estimates from flux tower and MODIS satellite data, Remote Sens. Environ., 106, 285-304, 2007.

Crago, R. D.: Conservation and variability of the evaporative fraction during the daytime, J. Hydrol., 180, 173-194, 1996.

Daamen, M.: Estimation of large scale daily evapotranspiration using geostationary meteorological satellite observations, Wageningen University, MSc thesis, 2008.

Doorenbos, J. and Pruitt, W. O.: Crop water requirements, FAO Irrigation and Drainage Paper No. 24 (revised), Food and Agriculture Organization, Rome, Italy, 1977.

Fermor, P. M., Hedges, P. D., Gilbert, J. C., and Gowing, D. J. G.: Reedbed evapotranspiration rates in England, Hydrol. Process., 15, 621-631, 2001.

Gao, Z., Bian, L., Lu, C., Lu, L., Wang, J., and Wang, Y.: Estimation of aerodynamic parameters in urban areas, J. Appl. Meteorol. Sci., 13, 16-34, 2002.

Gillies, R. R. and Carlson, T. N.: Thermal remote sensing of surface soil water content with partial vegetation cover for incorporation into climate models, J. Appl. Meteorol., 34, 745-756, 1995.

Gurney, R. J. and Hsu, A. Y.: Relating evaporative fraction to remotely sensed data at the FIFE site. Symposium on FIFE, First ISLSCP Field Experiment, American Meteorological Society, Boston, MA, 112-116, 1990.

He, Y., Su, Z., Jia, L., Zhang, Y., Roerink, G., Wang, S., Wen, J., and Hou, Y.: Estimation of Daily Evapotranspiration in Northern China Plain by Using MODIS/TERRA Images, in: Proceedings of SPIE, Volume 5976, Remote Sensing for Agriculture, Ecosystems, and Hydrology VII, Manfred Owe, Guido D'Urso, Editors, 413-424, 2005.

Jia, L. and Daamen, M.: Estimation of large scale daily evapotranspiration using geostationary meteorological satellite observations, Geophysical Research Abstracts, 11, EGU2009-7207, EGU General Assembly 2009, 2009.

Jia, L., Menenti, M., Nerry, F., Najjar, G., Stoll, M. P., and Su, Z.: Evaluation of the Surface Energy Balance Index with the field and airborne data collected at Hartheim and Colmar, Proceddings of the Final Results workshop on DAISEX (Digital Airborne Spectrometer EXperiemnt), (15-16 March, 2001), ESTEC-ESA, SP-499, 235-240, 2001.

Jia, L., Su, Z., van den Hurk, B. J. J. M., Menenti, M., Moene, A. F., de Bruin, H. A. R., Baselga Yrisarry, J. J., Ibanez, M., and Cuesta, A.: Estimation of sensible heat flux using the Surface Energy Balance System (SEBS) and ATSR measurements, J. Phys. Chem. Earth, 8, 75-88, 2003.

Jia, L.: Modeling heat exchanges at the land-atmosphere interface using multi-angular thermal infrared measurements, Wageningen University, ISBN 90-8504-041-8, 199 pp., 2004.

Jia, L., Xi, G., Liu, G., Huang, C., Liu, S., Song, S., and Lian, Y.: Wetland vegetation water consumption over the natural reserve area in Yellow River Delta, in: Proceedings of the 3rd International Yellow River Forum (IYRF), Dongying, China, 16-19 Oc- tober, 2007.

Jiang, L. and Islam, S.: A Methodology for Estimation of Surface Evapotranspiration over Large Areas using Remote Sensing Observations, Geophys. Res. Lett., 26, 2773-2776, 1999.

Kustas, W. P. and Daughtry, C. S. T.: Estimation of the soil heat flux/net radiation ratio from spectral data, Agr. Forest Meteorol., 49, 205-223, 1989.

Kustas, W. P. and Norman, J. M.: Evaluation of soil and vegetation heat flux predictions using a simple two-source model with radiometric temperatures for partial canopy cover, Agr. Forest Meteorol., 94, 13-29, 1999.

Leuning, R., Zhang, Y., Rajaud, A., Cleugh, H., and Tu, K.: A simple surface conductance model to estimate regional evaporation using MODIS leaf area index and the Penman-Monteith equation, Water Resour. Res., 44, W10419, doi:10.1029/2007WR006562, 2008.

Liang, S.: Narrowband to broadband conversions of land surface albedo - Algorithms, Remote Sens. Environ., 76, 213-238, 2000.

Massman, W. J.: An analytical one-dimensional model of momentum transfer by vegetation of arbitrary structure, Bound.-Layer Meteorol., 83, 407-421, 1997.

Menenti, M. and Ritchie, J. C.: Estimation of effective aerodynamic roughness length of Walnut Gulch watershed with laser altimeter measurements, Water Resour. Res., 30, 1329-1337, 1994.

Menenti, M. and Choudhury, B. J.: Parameterization of land surface evapotranspiration using a location-dependent potential evapotranspiration and surface temperature range, in: Exchange Processes at the Land Surface for a Range of Space and Time Scales, edited by: Bolle, H. J., Feddes, R. A., and Kalma, J. D., IAHS Publ., 212, 561-568, 1993.

Menenti, M., Azzali, S., Verhoef, W., and van Swol, R.: Mapping agroecological zones and time lag in vegetation growth by means of Fourier analysis of time series of NDVI images, Adv. Space Res., 13(5), 233-237, 1993.

Menenti, M., Bastiaanssen, W. G. M., Hefny, K., and Abd El Karim, M. H.: Mapping of groundwater losses by evaporation in the Western Desert of Egypt, Report 43, DLO Winand Staring Centre, Wageningen, The Netherlands, 116 pp., 1991.

Moran, M. S., Clarke, T. R., Inoue, Y., and Vidal, A.. Estimating crop water deficit using the relation between surface-air temperature and spectral vegetation index, Remote Sens. Environ., 49, 246-263, 1994.

Monteith, J. L.: Principles of Environmental Physics, Edward Arnold Press, 241 pp., 1973.

Mu, Q., Heinsch, F. A., Zhao, M., and Running, S. W.: Development of a global evapotranspiration algorithm based on MODIS and global meteorology data, Remote Sens. Environ., 111, 519536, 2007.

Nemani, R. and Running, S. W.: Estimation of regional surface resistance to evapotranspiration from NDVI and Thermal_IR AVHRR data, J. Appl. Meteorol., 28, 276-284, 1989.

Nishida, K., Nemani, R. R., Glassy, J. M., and Running, S. W.: Development of an evapotranspiration index from Aqua/MODIS for monitoring surface moisture status, IEEE T. Geosci. Remote, 41, 493-501, 2003.

Norman, J. M., Kustas, W. P., and Humes, K. S.: Source approach for estimating soil and vegetation energy fluxes in observations of directional radiometric surface temperature, Agr. Forest Meteorol., 77, 263-293, 1995. 
Peacock, C. E. and Hess, T. M.: Estimating evapotranspiration from a reed bed using the Bowen-ratio energy balance method, Hydrol. Process., 18, 247-260, 2004.

Raupach, M. R.: Drag and Drag partition on rough surfaces, Bound.-Lay. Meteorol., 60, 375-395, 1992.

Raupach, M. R: Simplified expressions for vegetation roughness length and zero-plane displacement height as functions of canopy height and area index (research note), Bound.-Lay. Meteorol., 71, 211-216, 1994.

Roerink, G. J., Menenti, M., and Verhoef, W.: Reconstructing cloud-free NDVI composites using Fourier analysis of time series, Int. J. Remote Sens., 21(9), 1911-1917, 2000a.

Roerink, G. J., Su, B., and Menenti, M.: S-SEBI A simple remote sensing algorithm to estimate the surface energy balance, Physics Chim Earth (B) 25(2), 147-157, 2000b.

Shuttleworth, W. J., Gurney, R. J., Hsu, A. Y., and Ormsby, J. P.: FIFE: the variation in energy partition at surface flux sites, IAHS Publ., 186, 67-74, 1989.

$\mathrm{Su}, \mathrm{Z}$.: Hydrological application of remote sensing: Surface fluxes and other derived variables - Surface energy balance (latent and sensible heating, net radiation), in: Encyclopedia of Hydrological Sciences, edited by: Anderson, M., John Wiley, Chichester, UK, 1-22, 2005.
Su, Z.: The Surface Energy Balance System (SEBS) for estimation of turbulent heat fluxes, Hydrol. Earth System Sci., 6(1), 85-99, 2002.

Sugita, M. and Brutsaert, W.: Daily evaporation over a region from lower boundary layer profiles measured with radiosondes, Water Resour. Res., 27, 747-752, 1991.

Verhoef, W., Menenti, M., and Azzali, S.: A colour composite of NOAA-AVHRR-NDVI based on time series analysis 19811992, Int. J. Remote Sens., 17, 231-235, 1996.

Verhoef, W.: Application of Harmonic Analysis of NDVI Time Series(HANTS), in: Fourier analysis of temporal NDVI in the Southern African and American continents, edited by: Azzali, S. and Menenti, M., Report of DLO Winand Staring Centre, Wageningen, The Netherlands, 1996.

Zhang, R.: Experimental Remote Sensing Modeling and Surface Foundations, Science Press, Beijing, 1996 (in Chinese). 